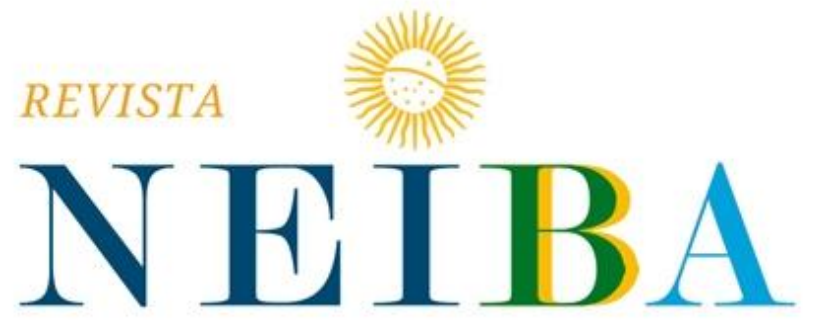

CADERNOS ARGENTINA-BRASIL
Volume 10,2021, p. $01-23$

DOI: 10.12957/neiba.2021.58897 | e58897 IISSN: 2317-3459

\title{
DIREITOS REPRODUTIVOS E COLONIALIDADE DE GÊNERO NA AMÉRICA LATINA: A INSTRUMENTALIZAÇÃO INTERNACIONAL DAS POLÍTICAS DE CONTROLE POPULACIONAL DO GOVERNO FUJIMORI
}

DERECHOS REPRODUCTIVOS Y COLONIALIDAD DE GÉNERO EN AMÉRICA LATINA: LA INSTRUMENTALIZACIÓN INTERNACIONAL DE LAS POLÍTICAS DE CONTROL DE POBLACIÓN DEL GOBIERNO DE FUJIMORI

\section{Eduarda Racoski Cortelini ${ }^{1}$}

${ }^{1}$ Universidade Federal de Santa Maria (UFSM), Santa Maria, RS, Brasil. E-mail: eduardaracoski@gmail.com ORCID: https://orcid.org/0000-0001-8095-7766

\section{Renata Rodrigues Marques ${ }^{2}$}

2Universidade Federal de Santa Maria (UFSM), Santa Maria, RS, Brasil. E-mail: renatarodriguesm@mail.ufsm.br ORCID: https://orcid.org/0000-0002-5108-6313

Recebido em: 03/04/2021 | Aceito em: 13/09/2021.

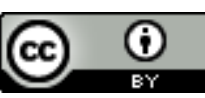

Esta obra está licenciada com uma Licença Creative Commons Atribuição 4.0 


\section{RESUMO}

Este trabalho objetiva analisar a responsabilidade da Organização das Nações Unidas (ONU) nas políticas de controle demográfico que resultaram na esterilização forçada de mulheres indígenas rurais no governo de Alberto Fujimori (1990-2000), no Peru. Buscase compreender como esforços internacionais de controle populacional para América Latina influenciaram em políticas públicas de esterilização forçada de mulheres, no Peru, promovendo políticas de branqueamento populacional. Este Estudo de Caso utiliza-se da Análise de Discurso de documentos da ONU e do governo peruano, a fim de argumentar que essas organizações, utilizando-se pautas feministas, serviram enquanto instrumento da colonialidade de gênero, esterilizando sistematicamente mulheres rurais e indígenas. Resultados demonstram que Fujimori teve atuação em conferências internacionais, e que as Nações Unidas foram instrumento para essas políticas. Conclui-se que esforços internacionais para o controle demográfico na América Latina convergiram com o programa peruano, e que esse arranjo resultou na esterilização forçada de aproximadamente 200 mil mulheres.

Palavras-chave: Direitos Reprodutivos; Colonialidade de Gênero; Governo Fujimori.

\section{RESUMEN}

Este trabajo tiene la intención de analizar la responsabilidad de la Organización de las Naciones Unidas (ONU) en las políticas de control demográfico que resultaron en la esterilización de mujeres indígenas rurales bajo el gobierno de Alberto Fujimori (19902000), en Perú. Se trata de comprender cómo los esfuerzos internacionales de control poblacional para América Latina incidieron en las políticas públicas de esterilización forzada de mujeres en el Perú. Este Estudio de Caso utiliza el Análisis del Discurso de documentos de la ONU y del gobierno peruano, teniendo la hipótesis de que las organizaciones, utilizando lineamientos feministas, sirvieron como un instrumento de colonialidad de género, esterilizando sistemáticamente a mujeres rurales e indígenas. Los resultados demuestran que Fujimori ha trabajado en conferencias internacionales y que las Naciones Unidas ha sido un instrumento para esas políticas. Se concluye que los esfuerzos para controlar la demografía en América Latina convergieron con el programa 
peruano, y que ese arreglo resultó en la esterilización forzada de aproximadamente 200 mil mujeres.

Palabras Clave: Derechos Reproductivos; Colonialidad de Género; Gobierno de Fujimori.

\section{INTRODUÇÃO}

O governo de Alberto Fujimori (1990-2000) no Peru é hoje responsável por um dos maiores casos de violação de direitos sexuais e reprodutivos na América Latina. Através de uma política de controle populacional, o governo realizou a esterilização forçada de aproximadamente 200 mil mulheres indígenas peruanas, que não tinham ciência ou concordavam com esse procedimento. Este artigo analisa de que forma o governo Fujimori utilizou-se da narrativa que reforça a ideia de que a pobreza e o subdesenvolvimento na região são fruto do crescimento populacional desenfreado para utilizar as instituições internacionais enquanto ferramenta útil de suporte a essas políticas.

Assim, discutiremos que apesar de o governo Fujimori ser um governo autoritário com práticas econômicas neoliberais, a responsabilização pelas políticas de controle populacional no Peru também perpassa as organizações internacionais, demonstrando que a colonialidade de gênero, como bem pensada por María Lugones (2008), é essencial para entender de que maneira as violências que as mulheres racializadas sofrem são indiferentes à estrutura colonial e patriarcal. Dessa forma, pelo fato de a maioria das mulheres esterilizadas serem mulheres indígenas, é crucial compreender como esse sistema colonial de gênero atua para legitimar políticas de branqueamento racial contra mulheres indígenas e negras.

Isso posto, abordaremos a seguintes questões: Como esforços internacionais de controle populacional para América Latina influenciaram em políticas públicas de esterilização forçada de mulheres, no Peru, promovendo políticas de branqueamento populacional? Enfocaremos no papel da Organização das Nações Unidas nesse processo. Essa análise será orientada pelos conceitos de interseccionalidade de configurações de poder (Crenshaw, 2002; Davis, 2003), Colonialidade de Gênero (Lugones, 2008) e Corpo Colonial (Fanon, 2008; Gomes, 2013), que serão desenvolvidos na primeira seção. 
Argumentamos que o discurso sobre a necessidade de uma política de controle de natalidade impulsionou e serviu de justificativa para uma política de branqueamento populacional e de violação sistemática do corpo de mulheres indígenas peruanas, que recebeu apoio e suporte de organizações internacionais como a ONU.

A relação entre direitos reprodutivos e políticas de controle populacional têm sido desenvolvida em publicações internacionais e nacionais (Dixon-Mueller, 1993; Hartmann, 1995; Roland, 1995; Corrêa e Petchesky, 1996; Giffin, 2002; Davis, 2003; Connelly, 2009), que enfocam na denúncia de programas eugenistas de controle populacional e em repensar os direitos reprodutivos enquanto parte de uma preocupação ampla com a saúde coletiva. Percebemos que o movimento feminista que se internacionaliza, a partir dos anos 1960, prioriza a reivindicação por "direitos de não reproduzir" (Giffin, 2002) -, dessa forma, o enfoque no controle da fecundidade tem participação feminista na promoção a agenda internacional de controle populacional no Terceiro Mundo. Os programas que enfocam na diminuição das taxas de fecundidade utilizaram-se da autonomia e saúde dos corpos femininos enquanto discursos legitimadores, apesar de isso não ser prioridade na implementação desses (Corrêa e Petchesky, 1996; Giffin, 2002).

Visamos contribuir com essa literatura partindo de uma perspectiva das Relações Internacionais, investigando as manifestações institucionais que, no ambiente internacional, apoiaram discursivamente e financeiramente a atuação estatal no caso peruano. Nosso argumento se localiza nas distinções entre os discursos e as práticas, uma vez que os discursos (tanto do Estado quanto das instituições) são utilizados enquanto meios para justificar práticas que nada favorecem os direitos reprodutivos e autonomia dos corpos de fato (Coe, 2004; Boesten, 2007; Stavig, 2017). Percebemos que a construção do "mito da superpopulação", também pela agenda internacional, é baseada em políticas de medo que se utilizam de corpos de mulheres enquanto instrumentos de políticas Malthusianas, com fins eugenistas (Hartmann, 1995).

Para fins metodológicos, utilizamos a combinação entre Estudo de Caso enquanto método e a Análise de Discurso enquanto técnica de análise (Ragin, 2009; Neumann, 2008). Os documentos escolhidos para esta análise foram o discurso de Fujimori na 
Quarta Conferência Mundial sobre Mulheres em Pequim, patrocinada pela ONU em 1995, o Programa de Salud Reproductiva y Planificación Familiar (1996-2000) do governo de Fujimori, e O programa de Ação da Conferência Internacional de População e Desenvolvimento (International Conference on Population and Development - ICPD, em inglês) de 1994.

A fim de esclarecer o que será analisado nos discursos e documentos, estabelecemos duas categorias a serem exploradas: (i) a categoria de Direitos Reprodutivos, e (ii) a categoria de Políticas Estatais de controle populacional. Entendemos que essas categorias, ainda que estejam relacionadas, são distintas. Os direitos reprodutivos surgem de reivindicações feministas e enfocam no direito de escolha e autonomia dos corpos em decidir ter ou não filhos, bem como ao acesso amplo de informações, acesso à saúde, métodos contraceptivos, e o direito de interromper uma gravidez indesejada. Além disso, também emergiram debates sobre condições necessárias para exercício da maternidade (Giffin, 2002). Por outro lado, assumimos, para fins analíticos, que Políticas Estatais de controle populacional, incluindo o Programa de Planejamento Familiar que será analisado, objetivavam o controle populacional coercitivo acima da garantia de direitos reprodutivos (Connelly, 2009), apesar de se utilizarem desses enquanto discurso legítimo de suas políticas, dada as justificativas apresentadas. A tabela abaixo exemplifica as categorias e seus principais componentes:

Tabela 1: Categorias e componentes utilizados na análise dos documentos.

\begin{tabular}{|c|c|}
\hline Categorias & Componentes \\
\hline I. Direitos Reprodutivos & $\begin{array}{l}\text { i. autonomia e liberdade de escolha: acesso à métodos } \\
\text { contraceptivos, serviços de saúde, e interrupção de } \\
\text { gravidez (se desejada) } \\
\text { ii. oposição às políticas conservadoras } \\
\text { iii. condições para exercício de maternidade }\end{array}$ \\
\hline $\begin{array}{l}\text { II. Políticas Estatais de } \\
\text { controle populacional }\end{array}$ & $\begin{array}{l}\text { i. "planejamento familiar" } \\
\text { ii. preocupação econômica (pobreza) relacionada com taxas }\end{array}$ \\
\hline
\end{tabular}


\begin{tabular}{|l|l|}
\hline & \multicolumn{1}{|c|}{ de natalidade } \\
& $\begin{array}{l}\text { iii. metas a serem cumpridas } \\
\text { iv. não preocupação com autonomia na escolha do melhor } \\
\text { contraceptivo }\end{array}$ \\
\hline
\end{tabular}

Fonte: elaboração das autoras.

O artigo é estruturado na seguinte forma: na primeira seção exploramos de que maneira a construção discursiva da pobreza na América Latina como fruto da alta taxa de natalidade legítima políticas higienistas e racistas e contribui para um processo estrutural de branqueamento racial. Na segunda seção analisamos as políticas coloniais e patriarcais do governo Fujimori, e a forma como a cooptação do discurso dos "direitos das mulheres" foi feita em seu Programa de Planejamento Familiar. Por último, realizamos a análise dos discursos e documentos das Nações Unidas sobre as políticas de controle de natalidade ressaltando a importância simbólica dos organismos cederem espaço para o governo Fujimori e apoiarem o plano de planejamento familiar. Por fim, apresentamos as conclusões sobre nossas reflexões que pretendem lançar um novo olhar sobre a esterilização forçada no Peru, de nenhuma maneira isentando o governo Fujimori de sua responsabilidade por perpetuar práticas de violência, mas sim, ressaltando também o papel de organizações internacionais no apoio a essas políticas.

\section{PERSPECTIVA INTERSECCIONAL DAS POLÍTICAS DE CONTROLE POPULACIONAL NA}

\section{AMÉRICA LATINA}

Enquanto publicava As Veias Abertas da América Latina, em 1971, Eduardo Galeano já compreendia a violência sistemática presente nas políticas de controle populacional ao continente, prescritas por uma agenda internacional construída externamente. O continente que, em um primeiro momento, utilizou-se de políticas pró-natalistas afim de aumentar sua população - inclusive negando a utilização de produtos contraceptivos e o acesso a direitos reprodutivos mínimos às mulheres -, passa por um processo inverso a partir das décadas de 1960-1970, sendo influenciado por propostas externas de políticas de planejamento familiar, apontadas por diversas conferências internacionais que 
abordaram a temática ${ }^{2}$. Esses esforços objetivavam, ao fim e ao cabo, diminuir os níveis de fecundidade da população (Miró, 1987).

Essas políticas se relacionam com características presentes no processo de formação dos Estados Nacionais na América Latina: o modelo de governo estabelecido foi "importado", perpassando pela concessão de soberania no ambiente internacional ao mesmo tempo em que se obtinha controle reduzido do território e da população. O resultado dessa construção histórica perpassa por processos violento de homogeneização das comunidades nacionais, e utilização da coerção contra a população originária nesses territórios (Tilly, 1996, p. 296; Giddens, 1986).

Nesse primeiro momento, o continente é tomado por políticas eugenistas baseadas em ideias estabelecidas de hierarquia racial (Martínez-Echazábal, 1998) e, como consequência, os Estados Nacionais se constituem enquanto "administradores de etnias" (Segato, 1999). No período pré-colonização, portugueses e espanhóis se estruturaram enquanto sociedades altamente hierarquizadas, onde a dimensão racial teve um importante papel de articulação das castas sociais (Gonzalez, 1988/2020). De acordo com Lélia Gonzalez (1988/2020), sendo as sociedades latino-americanas herdeiras históricas das ideologias de classificação social (racial e sexual) essas se constituíram também enquanto hierárquicas e racialmente estratificadas.

Sendo assim, "o racismo latinoamericano é suficientemente sofisticado para manter negros e indígenas na condição de segmentos subordinados no interior das classes mais exploradas, graças a sua forma ideológica mais eficaz: a ideologia do branqueamento [...]" (Gonzalez, 1988/2020, p. 139-151). A partir disso, a forma colonial e patriarcal que os Estados latino-americanos operam, transmitida pelos sistemas ideológicos tradicionais e pelos meios de comunicação, faz com que o mito da superioridade branca comprove sua eficácia através da desintegração violenta, de fragmentação da identidade étnica e do desejo de embranquecimento (Gonzalez, 1988/2020).

\footnotetext{
2 Conferências internacionais sobre políticas de controle populacional na América Latina nos anos 60-70: Primeira Assembleia Pan-Americana de População, 1965; Reunião da Organização dos Estados Americanos (OEA), em 1967, sobre Políticas de População em relação ao Desenvolvimento da América Latina; Conferência Regional LatinoAmericana de População, 1970; Plano de Ação Mundial sobre População - Conferência de Bucareste, 1974.
} 
Neste contexto, as políticas violentas e forçadas de controle de natalidade da região, são, como consequência, fruto da formação histórica da sociedade latino-americana hierarquizada racialmente e do desejo de branqueamento populacional. Por esse motivo, a nossa análise do caso é feita através dessa perspectiva por nos permitir aprofundar historicamente as consequências destrutivas do período colonial e entender como esse sistema colonial/moderno de gênero opera atualmente. Partimos do entendimento de que políticas de controle populacional analisadas a partir de perspectivas neutras que não abarcam internacionalmente as configurações sociais de poder, não só de gênero como também de raça e classe (Giffin, 2002; Davis, 2003; Crenshaw, 2002). Quando analisamos a partir da perspectiva interseccional, percebemos que essas políticas não resultaram em ganhos, mas em processos violentos de controle de natalidade.

Em uma recapitulação histórica da segregação racial e de gênero, Angela Davis (2003) expõe as dicotomias entre as pautas do movimento sufragista (branco) em detrimento das pautas do movimento negro, analisando o impacto de políticas de controle populacional para mulheres racializadas. Nesse sentido, o que era demandado como um direito essencial para as mulheres brancas (o controle de seu corpo nas questões reprodutivas), passou a ser entendido como uma obrigação para as mulheres racializadas e pobres. O movimento em prol do controle da natalidade, a partir daí, tornou-se uma política racista, perdendo sua capacidade enquanto política progressista de direitos individuais ao controle da natalidade e transformando-se em uma estratégia racista de controle populacional (Davis, 2003).

Parte-se disso para incluir o conceito de Corpo Colonial, construído por Franz Fanon (2008), que identifica um processo de subjetivação partindo do corpo enquanto território (coletivo) marcado por estruturas de dominação. O Corpo Colonial, caracterização do sujeito colonizado, está marcado por discursos raciais que também operam em uma perspectiva interseccional - de gênero, classe, sexualidade (Gomes, 2013).

Numa perspectiva afrolatinoamericana, Lélia Gonzalez (1988/2020) afirma que as mulheres não brancas passam por um processo de dominação que, ao colocá-las como inferior, as infantiliza, suprimindo os seus direitos de agência e humanidade. Essas desigualdades que marcam as mulheres não brancas na região devido ao duplo caráter 
de sua condição biológica (racial e sexual) faz com que essas estejam representadas no conceito de Corpo Colonial, e tenham suas necessidades invisibilizadas na elaboração de políticas mais amplas de saúde sexual e reprodutiva. Neste caso, a grande maioria dos programas de controle de taxa de natalidade foram pensados dentro de uma ótica branca de direitos individuais, que não contempla, de nenhuma maneira, a realidade das mulheres latino-americanas.

Olhando para a questão dos direitos reprodutivos das mulheres na realidade brasileira, Roland (1995) constata como e por que razão os programas de redução da taxa de fecundidade foram dirigidos ao Nordeste do país, através de recursos privados injetados nas Secretarias de Saúde. A concepção de que a diminuição da taxa de natalidade pudesse reduzir a pobreza no país mostrou-se errada, uma vez que as mulheres começaram a ter cada vez menos filhos, mas as mulheres pobres continuaram pobres (Roland, 1995). O principal argumento da autora é que a fecundidade foi reduzida no Brasil a um custo altíssimo pago pelas mulheres, sem que se alterasse a cruel concentração de renda no país. Dessa forma, o que foi vendido como a solução para a pobreza e o subdesenvolvimento tornou-se uma política que ocasionou a diminuição da população negra.

A partir disso, pensamos o caso de esterilização forçada de mulheres indígenas peruanas sob a ótica da Colonialidade de Gênero. Portanto, refletir sobre o sistema moderno/colonial de gênero é reconhecer o gênero enquanto uma imposição colonial, que violentamente inferioriza as mulheres colonizadas (Lugones, 2008). Sendo assim, o patriarcado moderno é entendido enquanto parte de uma construção histórica diretamente relacionada à colonização (Lugones, 2008; Oyěwùmí, 2004).

Assim, a raça não configura, por si só, a colonialidade do poder pensada por Quijano, mas para o feminismo descolonial, ela é acompanhada pelo gênero e pela sexualidade (Lugones, 2008). Quando o poder colonial é analisado em conjunto ao poder patriarcal, entende-se o uso sistemático do corpo das mulheres colonizadas como um "território" a ser conquistado e ocupado pelo colonizador (homem, branco, cristão, europeu e heterossexual), que leva violação do corpo feminino repetir-se histórica e violentamente (Ballestrin, 2017). 
Nesse sentido, o sistema de gênero moderno/colonial se perpetua através de estruturas de poder, aqui apresentados sendo, sobretudo, o Estado e as organizações internacionais. Abordagens feministas têm percebido que instituições e organizações sociais são uma das dimensões construídas através de uma visão patriarcal que sustentam relações de poder, ampliando a noção de gênero para um aspecto político (Scott, 1990). Assim sendo, partimos da concepção de interseccionalidade de configurações de poder para entender as políticas de planejamento familiar e controle populacional, percebendo o Corpo Colonial e a Colonialidade de Gênero enquanto estruturas que marcam os discursos institucionais internos (Estado) e externos (Organização das Nações Unidas), que serão explorados na próxima seção.

\section{A ATUAÇÃO ESTATAL: POLÍTICAS DE PLANEJAMENTO FAMILIAR NO PERU (1995-2000)}

A adoção de políticas de controle populacional na América Latina é construída enquanto parte de políticas de desenvolvimento econômico onde a "legitimidade internacional" - ou seja, a pressão internacional - é concebida antes mesmo da adoção interna nos países (tal qual a construção de soberania). Um dos exemplos dos discursos externos que permearam os debates se deu na Conferência Regional Latino-Americana de População (1970), onde o posicionamento do governo dos Estados Unidos era a recomendação de controle das taxas de fecundidade, associando o 'problema' do crescimento populacional enquanto diretamente relacionado com os problemas sociais e econômicos da região (Miró, 1987). Essa posição foi fortemente replicada pelos países latino-americanos, que não chegavam a um consenso sobre como deveriam se estabelecer políticas de população. Todavia, na Conferência Mundial de População em Bucareste (1975) já estava disseminada a concordância de posicionamento dos países quanto à relação direta entre políticas de desenvolvimento econômico e social e controle demográfico. O resultado disso foi o desenvolvimento de programas nacionais públicos de planejamento familiar. Devemos mencionar que, antes de estratégias semelhantes se tornarem políticas públicas, já estavam sendo denunciadas práticas de esterilização de mulheres pobres e indígenas na América Latina, financiada por organizações internacionais (estadunidenses e europeias) (Galeano, 1971; Boesten, 2007). 
No caso analisado, podemos mencionar que as mudanças de políticas populacionais peruanas se iniciaram antes do governo de Fujimori, ainda que de maneira tímida. Nesse período, movimentos feministas organizados urbanos e de classe média pediam a legalização da esterilização voluntária e do aborto, todavia, o acesso à informação e políticas de saúde não chegava às áreas rurais (Boesten, 2007). A estratégia de controle de natalidade no Peru não foge da difusão histórica de pensamentos eugenistas no Terceiro Mundo que, se utilizando de diversos argumentos (econômicos, científicos e até mesmo ambientalistas), visavam modificar a estrutura 'racial' nessas sociedades e lidar com o "problema indígena" a partir do branqueamento da população (Boesten, 2007), até mesmo enquanto estratégia de construção da identidade nacional (MartínezEchazábal, 1998).

A implementação do programa teve como consequência a esterilização em massa de mulheres pobres, majoritariamente indígenas e campesinas. Estima-se que eram indígenas pelo menos $95 \%$ das mulheres esterilizadas, de acordo com dados oficiais do governo peruano. Cerca de 270 mil mulheres no total passaram pelo processo de ligadura de trompas, muitas dessas de maneira enganosa e de forma comprovadamente forçada (Peru, 2002).

O Programa de Planejamento Familiar foi apresentado internacionalmente pelo presidente ao discursar na Conferência Mundial sobre Mulheres patrocinada pela Organização das Nações Unidas. Fujimori foi o único chefe de Estado homem a discursar (Boesten, 2007; Stavig, 2017). O que podemos observar a partir da análise de discurso é o enfoque principal em duas características: (i) o presidente se constrói enquanto um líder em oposição ao conservadorismo disposto, inclusive, a enfrentar uma das principais instituições de poder do país (a Igreja Católica) em nome dos direitos reprodutivos das mulheres; (ii) o enfoque na pobreza e na situação de mulheres pobres (mencionadas 13 vezes) enquanto prioridade de seu governo: "Eu sei muito sobre os problemas das mulheres, especialmente mulheres pobres. [...] A pobreza tem cara de mulher. A pobreza em nossos países atinge as mulheres duas vezes mais em tempos de crise" (Fujimori, 1995). 
Fujimori se apresenta a fim de construir empatia com a audiência admitindo sua posição enquanto parte da "estrutura de poder masculina", (Fujimori, 1995). Em diversas parte do discurso ele constrói o antagonismo às forças conservadoras, estabelecendo que "a hierarquia da Igreja Católica está reagindo [...] de maneira desproporcional" e que "as mulheres peruanas não ficarão confinadas ou constrangidas pela intransigência de mentalidades ultraconservadoras que pretendem transformar em dogma sua incapacidade de aceitar a mudança social". É perceptível, ao longo dessa construção discursiva, seu empenho pelo assentimento de movimento feministas internacionais em relação ao programa de planejamento familiar, enquanto um projeto positivo e progressista em relação ao acesso à saúde e direitos das mulheres (Fujimori, 1995).

O presidente parte das metas de redução da pobreza para apresentar o programa de planejamento familiar, enquanto "parte de uma política de desenvolvimento social e combate à pobreza", mencionando a preocupação com a sobrecarga das tarefas femininas e a sobrecarga de se ter muitos filhos. Nesse momento, ele também enfatiza a autonomia das mulheres nesse processo. Fujimori menciona abertamente a esterilização enquanto uma vitória contra o conservadorismo (as vasectomias e ligaduras de trompas haviam sido recentemente aprovadas pelo congresso peruano) e enquanto método contraceptivo que possa assegurar que as mulheres sejam as donas de seu destino no século XXI" (Fujimori, 1995). O discurso é recebido pela comunidade internacional de maneira extremamente positiva, levando inclusive o governo peruano a receber milhões de dólares e outros recursos da Agência dos Estados Unidos para o Desenvolvimento Internacional (USAID) para desenvolver seu programa.

Diversas partes de discursos de Fujimori são citadas já na segunda página do Programa de Saúde Reprodutiva, analisado em seguida. Sua apresentação demonstra que o objetivo central do plano seria enfocar na saúde da população, "com ênfase em grupos menos protegidos" (Peru, 1996, p. 3), mencionando, inclusive, o artigo 6o da constituição do país que estabelece "o direito de famílias e indivíduos de decidir livremente o número de filhos que desejam ter" e o "consentimento livre e voluntário" (Peru, 1996, p. 3). Como previsto pelo discurso do presidente no ano anterior, a saúde reprodutiva é um dos termos mais mencionados no projeto, sendo estabelecida 
enquanto "um direito primário que o estado prevê e reconhece". Outro enfoque está no desenvolvimento econômico e na mobilização de recursos, entendendo o estabelecimento de metas demográficas enquanto parte das "demandas e expectativas da população peruana" em sua totalidade.

No geral, as descrições do programa parecem extremamente compreensivas e conhecedoras da realidade social, econômica e política do país: reconhecem a desigualdade de gênero, de acesso à educação e de oportunidades para quem vive na zona rural "principalmente se pertencerem a grupos étnicos com línguas e padrões culturais próprios" (Peru, 1996). Há uma subseção dedicada especialmente à pobreza enquanto característica econômica e outra à "situação das mulheres", reconhecendo que isso "afeta as mulheres com maior impacto" (60\% das mulheres do país estão em situação de pobreza) (Peru, 1996, p. 10-11). O documento estabelece que a prioridade de acesso aos serviços do programa de planejamento familiar é em locais rurais e urbanos com maiores índices de pobreza (Peru, 1996, p. 42), e também menciona que "as famílias pobres têm mais membros do que o resto das famílias" (Peru, 1996, p. 42).

O programa reconhece que a limitação da fecundidade é algo desejado pelas mulheres do país (p. 15). Com isso, a esterilização feminina é mencionada em um primeiro momento enquanto um dos métodos mais conhecidos pelas mulheres em idade fértil (cerca de 80\%), depois da pílula e do dispositivo intrauterino. Esse também é reconhecido enquanto um dos métodos mais utilizados (8\%) nos anos anteriores ao programa (Peru, 1996, p. 15-16). As metas estabelecidas pelo programa relacionadas à fecundidade se propõem a chegar a uma taxa global de fecundidade de 2,5 filhos por mulher (Peru, 1996, p. 26). No final, o documento afirma que "a contribuição da cooperação internacional será fundamental para o início do plano" (Peru, 1996, p.56) a fim de implementar as "mudanças demográficas esperadas".

Enquanto conclusões preliminares das análises dos dois documentos, percebem-se que os discursos são comuns e complementares, principalmente quanto à "importância da saúde reprodutiva no processo de desenvolvimento" (Peru, 1996, p.29). A Resolução ministerial que aprova o programa enquanto um "instrumento técnico-normativo" também reforça essa característica. Enfatizando a desigualdade enquanto problema 
principal a ser combatido, o documento do programa chega a enfatizar a característica da esterilização enquanto instrumento para redução das desigualdades:

Portanto, o Governo está determinado a investir os recursos necessários para reduzir ao mínimo essa desigualdade. O primeiro passo foi declarar o fornecimento gratuito de todos os métodos anticoncepcionais modernos e seguros disponíveis para o programa, incluindo a anticoncepção cirúrgica voluntária. (Peru, 1996, p.28)

Outra característica mencionada no programa pode ser um indício da esterilização enquanto principal instrumento para as políticas populacionais. Diversas vezes no estabelecimento de objetivos específicos o documento enfatiza a "análise de custobenefício e custo-efetividade" para os métodos contraceptivos. A esterilização é mais tarde revelada enquanto um bom método custo-efetivo, demonstrando que as práticas do governo nada se relacionam de fato com a priorização da autonomia de escolha presente nos discursos:

O estabelecimento de cotas para esterilizar mulheres já é prova suficiente dos motivos políticos deste programa: estabelecer cotas implica seriamente que o programa não foi motivado por preocupações com a saúde da mulher, controle de natalidade ou mesmo planejamento familiar; tratava-se da demografia nacional em relação ao crescimento econômico. Essas metas também não foram definidas em uma área superpovoada; em vez disso, foram colocados em áreas rurais inacessíveis, pobres e marginalizadas. (Boesten, 2007, p. 07, tradução nossa)

Essa característica, somada ao estabelecimento de metas para redução das taxas de natalidade, permite o entendimento de como o discurso de direitos reprodutivos direitos das mulheres foi cooptado pelo governo de Fujimori. A partir disso, percebe-se que o indicador "mulheres pobres" (majoritariamente indígenas e campesinas), utilizado diversas vezes no discurso de Fujimori e no documento do programa, às estabelece enquanto corpos coloniais que servem enquanto instrumentos das políticas de controle e branqueamento populacional.

\section{A RESPONSABILIDADE INSTITUCIONAL DA ORGANIZAÇÃO DAS NAÇÕES UNIDAS}

A Conferência Internacional sobre a População e o Desenvolvimento (CIPD) foi uma conferência organizada pela ONU e ocorrida em Cairo no ano de 1994. A conferência também recebeu apoio do Fundo de População das Nações Unidas e da Divisão de População do Departamento de Informação Econômica e Social e Análise de Política das Nações Unidas. Com a participação de 179 Estados, obteve o consenso na elaboração de 
um Programa de Ação conjunto, destacando os vínculos entre as questões populacionais e o desenvolvimento e elencando metas relacionadas à educação, especialmente para meninas; igualdade e equidade entre os sexos; redução da mortalidade infantil e materna e acesso universal aos serviços de saúde reprodutiva, como o planejamento familiar (UNFPA, 2007). Apesar de não ser um debate novo no âmbito das Nações Unidas devido ao consenso internacional que emergiu desde a Conferência Mundial sobre População, realizada em Bucareste em 1974 e a Conferência Internacional de População, realizada na Cidade do México em 1984, a Conferência de 1994 foi considerada um marco para as questões de saúde reprodutiva e planejamento familiar. Seu grande diferencial era, sobretudo, era colocar as necessidades e os direitos dos indivíduos, e neste caso principalmente as mulheres, no centro do debate, ao invés de centrar apenas no controle do crescimento populacional como condição para a melhoria da situação econômica e social dos países (UNFPA, 2007).

Dada a densidade do relatório oficial da CIPD, foram selecionados os seguintes subcapítulos para a análise: 3.1) Capítulo 4.a - Emancipação e status da mulher; 3.2) Capítulo 7.a - Direitos de reprodução e saúde reprodutiva; 3.3) Capítulo 7.b Planejamento Familiar e, por fim a análise da declaração escrita do Peru sobre o Programa de Ação proposto na conferência.

No primeiro subcapítulo há uma grande ênfase no empoderamento e na autonomia da mulher, visando alcançar a igualdade da mulher na sociedade, assegurar a sua participação no desenvolvimento sustentável e na formulação de políticas, bem como assegurar o direito à educação plena. Termos como emancipação, autonomia, empoderamento e conscientização da mulher da plenitude de seus direitos legais aparecem cinco vezes ao longo do documento, tanto nos objetivos quanto nas ações previstas. Na justificativa de ação, destaca-se o seguinte trecho: “[...] a melhoria do status da mulher reforça também sua capacidade de tomar decisões em todos os níveis das esferas da vida, especialmente na área da sexualidade e da reprodução." (UNFPA, 2007, p.50). Nesse quesito, o seguinte trecho merece atenção: “O planejamento da saúde da família e outras intervenções de desenvolvimento devem levar em melhor conta as 
necessidades de tempo de uma mulher, decorrentes da responsabilidade da criação dos filhos, do trabalho doméstico e de atividades de geração de renda." (UNFPA, 2007, p. 52).

Na segunda seção analisada, discute-se amplamente sobre a questão de saúde reprodutiva. Aqui, entende-se saúde reprodutiva de uma forma que inclua o bem-estar físico, mental e social, de uma forma abrangente. Os termos "saúde reprodutiva" e "saúde sexual" aparecem vinte e sete vezes ao longo do subcapítulo. Destacam-se os termos "liberdade de decidir/escolha voluntária/escolha livre e consciente" (que aparecem quatro vezes) e a importância dos homens e mulheres possuírem "informações sobre saúde reprodutiva" (termos também citados quatro vezes). Sobre o direito à informação, destaca-se no documento a importância: "[...] de homens e mulheres de serem informados e de ter acesso a métodos eficientes, seguros, permissíveis e aceitáveis de planejamento familiar de sua escolha, assim como outros métodos, de sua escolha $[\ldots]^{\prime \prime}($ UNFPA, 2007, p. 62).

O subcapítulo sobre planejamento familiar enfatiza que "o princípio da livre escolha consciente é essencial ao sucesso em longo prazo de programas de planejamento familiar. Não há lugar para qualquer forma de coerção." (UNFPA, 2007, p. 64). Nesta seção, assim como nas anteriores, os termos "decisão livre/escolha consciente/consentimento voluntário" são bem frequentes, bem como a importância dos homens e mulheres de possuírem informações necessárias sobre saúde reprodutiva a fim de escolherem, de forma consciente, o melhor método. No documento, ainda consta que "objetivos demográficos, embora objeto legítimo de estratégias governamentais de desenvolvimento, não devem ser impostos aos prestadores de serviços de planejamento familiar na forma de alvos ou quotas no recrutamento de clientes." (UNFPA, 2007, p. 64).

Além disso, enfoca-se que "governos e a comunidade internacional devem lançar mão de todos os meios à sua disposição para apoiar o princípio da escolha voluntária no planejamento familiar" (UNFPA, 2007, p. 65). Como já mencionado, o documento objetiva frisar a autonomia e a escolha livre e consciente de métodos ideais que sejam adequados à realidade das famílias, como "reconhecer que métodos apropriados a casais e indivíduos variam de acordo com suas idades, partos, preferência pelo tamanho da 
família e outros fatores" (UNFPA, 2007, p. 66). E, como na seção analisada anteriormente, o método de esterilização não é mencionado.

O discurso oficial do Peru declara estar de acordo com o Plano de Ação proposto pela Conferência de 1994. No entanto, estabelece algumas ressalvas. O governo peruano solicita uma definição mais precisa de "saúde reprodutiva", "direitos de reprodução" e "controle de fecundidade", para que não haja possibilidade de o aborto ser permitido, levando em consideração apenas métodos que sejam compatíveis com o direito à vida, nas palavras do governo peruano.

Ao analisar discursivamente o Programa de Ação resultante da Conferência Internacional sobre a População e o Desenvolvimento, observa-se que há grande ênfase na autonomia e liberdade de decisão das mulheres e das famílias de decidirem o melhor método de planejamento familiar. Destaca-se a necessidade de as mulheres realizarem escolhas livres e conscientes, com base na ampla gama de informações sobre métodos contraceptivos e seus benefícios e malefícios. Também enfatiza a necessidade da adoção de métodos de planejamento familiar de forma voluntária, sem nenhuma coerção por parte dos governos e/ou de organizações não-governamentais. Questões que relacionam a pobreza e o subdesenvolvimento com altas de taxa de natalidade na região não são citadas no documento, ressaltando inclusive que as questões demográficas não devem sem o centro de questões de saúde reprodutiva e planejamento familiar. O Peru, enquanto participante da Conferência, ratificou esse Programa de Ação e estabeleceu apenas algumas ressalvas em relação ao aborto. Ainda assim, comprometeu-se com todos os objetivos e ações do Programa.

Como argumenta Giffin (2002), a introdução da questão da saúde reprodutiva na Conferência de Cairo foi celebrada como importante avanço, principalmente por aqueles que analisaram o Programa pelo viés dos estudos demográficos que, por sua vez, ocupavam-se exclusivamente com a diminuição das taxas de fecundidade. Contudo, "da perspectiva da situação vital das populações periféricas, por outro lado, é preciso indagar se enfocar a saúde nesse âmbito não representa um cerceamento da atenção, uma forma de evitar discussão das causas da pobreza e vulnerabilidade crescentes[...]." (Giffin, 2002, p. 104-105). 
A aplicação do Programa de Ação no Peru se deu de forma completamente contrária a todos pressupostos discutidos e apresentados na Conferência de 1994. De acordo com o Relatório Nada Personal do Comitê da América Latina e Caribe para a Defesa dos Direitos da Mulher (CLADEM), já no ano de 1996 havia denúncias da ocorrência de esterilizações forçadas em mulheres (majoritariamente indígenas) no Peru. Além disso, o governo havia estabelecido metas numéricas de anticoncepção cirúrgica a serem cumpridas, e por isso, muitas mulheres, principalmente pobres e campesinas, eram captadas e levadas à força para realizar o procedimento.

A investigação realizada pelo Comitê, que se deu a partir de milhares de depoimentos de mulheres que tiveram seus corpos violados, ressalta o programa foi guiado na prática por diretrizes e critérios afastados de um enfoque de direitos humanos, o que resultou em violações de liberdades e direitos fundamentais, que afetam de forma desproporcional e muito particular as mulheres em situação de pobreza, sobretudo indígenas e pobres. A partir dos relatos e dos exames de caso, é notável que o governo privilegiou os métodos irreversíveis de contracepção, dada a população com condições econômicas desfavoráveis, e induziu a esterilização como única opção, violando o direito de decidir de forma livre e voluntária entre a ampla gama de métodos contraceptivos disponíveis (CLADEM, 1999, p. 124).

Do mesmo modo, a violação da autonomia e a integridade corporal a partir da esterilização forçada foi especialmente prejudicial a mulheres rurais, que tiveram seu direito à informação negado, comprometendo seriamente sua autodeterminação. (CLADEM, 1999). Igualmente importante é salientar que tanto na Conferência de 1994 quanto na Convenção n 169 da OIT sobre Povos Indígenas e Tribais de 1989 destaca-se a importância de garantir a integridade e os direitos dos povos indígenas e a proteção de sua população. Em termos de saúde reprodutiva, os documentos destacam que a perspectiva indígena de população e desenvolvimento é muito diferente da população em um geral. Isso porque os povos indígenas, em muitas regiões, ainda apresentam um constante declínio populacional por diversos motivos, incluindo violações de direitos humanos e discriminação. Por isso os povos indígenas necessitam que as suas características demográficas tenham esforços especiais para serem compreendidas, 
incluindo a questão de saúde sexual e reprodutiva, destacando que todas as formas de coerção devem ser eliminadas (UNFPA, 2007).

\section{CONSIDERAÇÕES FINAIS}

As políticas de controle populacional no Peru foram diretamente motivadas por duas conferências promovidas pela Organização das Nações Unidas: a de Cairo, em 1994, sobre População e Desenvolvimento, e a Quarta Conferência Mundial sobre Mulheres em Pequim no ano de 1995. As duas conferências internacionais "conciliaram" os debates sobre programas populacionais e direitos reprodutivos, relacionando-os (Boesten, 2007). O problema que surge dessa narrativa é paradoxal para a luta dos direitos das mulheres: Organizações feministas de classe média demandaram acesso à diversos métodos contraceptivos. Para esse primeiro grupo, as políticas de planejamento familiar de Fujimori vinham ao encontro de suas demandas Em contrapartida, mulheres pobres e campesinas, majoritariamente indígenas, não possuíam o mesmo acesso à serviços de saúde e métodos contraceptivos, e encontraram-se vulneráveis à um programa de metas de esterilização em áreas rurais, promovido pelo governo autoritário de Fujimori, que não tinha preocupações reais com acesso à informação e autonomia corporal e visava alcançar objetivos econômicos.

Tabela 2: Resumo da análise dos documentos.

\begin{tabular}{|c|l|l|c|}
\hline Documentos & \multicolumn{1}{|c|}{ Categorias } & Termos Encontrados & Frequência \\
\hline (1) Discurso de & I. Direitos & - Autonomia de decisão & $1 / 7 / 15$ \\
Fujimori na & Reprodutivos & $(1 / 2 / 3)$ & \\
Conferência & & - Instituições & \\
Mundial sobre & & conservadoras (1) & 7 \\
Mulheres - & & - Saúde reprodutiva & \\
Pequim (1995) & & (1/2/3) & $0 / 22 / 12$ \\
(2) Programa de & & - Método & \\
saúde reprodutiva & & anticoncepcional (3) & 3 \\
\hline
\end{tabular}




\begin{tabular}{|c|c|c|c|}
\hline \multirow{2}{*}{$\begin{array}{l}\text { e planejamento } \\
\text { familiar (1996- } \\
\text { 2000) } \\
\text { (3) Programa de } \\
\text { Ação ICPD (1994) }\end{array}$} & & & 1 \\
\hline & $\begin{array}{l}\text { II. Políticas } \\
\text { Estatais de } \\
\text { controle } \\
\text { populacional }\end{array}$ & $\begin{array}{l}\text { - Pobreza, desigualdade } \\
\text { e desenvolvimento } \\
\text { social (1/2) } \\
\text {-Programas de } \\
\text { população (3) } \\
\text { - Planejamento familiar } \\
\text { (1/2/3) } \\
\text { - Esterilização (1/2/3) } \\
\text {-Recursos } \\
\text { Internacionais (1/2) } \\
\text {-Abortos ilegais (2) } \\
\text {-Métodos legais de } \\
\text { controle da } \\
\text { fecundidade (3) } \\
\text { - Metas (relacionadas à } \\
\text { taxa de fecundidade) } \\
\text { (1/2) }\end{array}$ & $\begin{array}{c}13 / 22 \\
2 \\
6 / 12 / 36 \\
1 / 6 / 0\end{array}$ \\
\hline
\end{tabular}

Fonte: elaboração das autoras.

Em relação à responsabilização das organizações internacionais no processo de esterilização forçada, é preciso destacar dois pontos: primeiro, o cumprimento das recomendações contidas no Programa de Ação é responsabilidade de cada país, possuindo então um status não-vinculativo. Contudo, o segundo ponto destaca que a ONU se compromete a vigiar a aplicação e prevê apoio financeiro para implementação do programa. Em suma, isso significa dizer que apesar da adoção do Programa de Ação 
por parte de cada país ser voluntária, a ONU reconhece a responsabilidade de fiscalizar a implementação e das ações do Programa estarem de acordo com seus princípios éticos de respeito aos direitos humanos.

Desse modo, respondemos nossa pergunta de pesquisa. Primeiro, entendendo que a implementação das políticas de controle populacional na América Latina (disfarçadas pelo discurso dos direitos reprodutivos) fazem parte de um processo maior que relaciona diretamente o controle demográfico com o desenvolvimento, incentivando políticas coercitivas de redução dos índices de natalidade. Segundo, percebendo que essas ideias estimulam políticas eugenistas que visam "embranquecer" a população do continente a partir da redução de taxas de natalidade principalmente de mulheres pobres e racializadas. E por fim, entendemos que a Organização das Nações Unidas, ao promover conferências internacionais e se comprometer com a fiscalização de ações relacionadas a direitos reprodutivos, não assumiu a responsabilidade que possuiu ao promover políticas de controle populacional enquanto processo para o desenvolvimento de países do Terceiro Mundo.

Por esses motivos, argumentamos que a ONU possui um grau de responsabilidade nas políticas de planejamento familiar que visavam o controle populacional de populações campesinas e indígenas no Peru. Partindo de uma perspectiva interseccional que entende a Colonialidade de Gênero enquanto parte estrutural da construção latinoamericana, entendemos que ao direcionar as suas políticas de planejamento familiar a mulheres campesinas e indígenas, o governo Fujimori cometeu uma violação de direitos dos povos indígenas, ao violar sistematicamente o corpo dessas mulheres, impedindo-as de terem filhos de maneira permanente. Isso se configurou a partir de uma política de controle populacional com elementos higienistas e racistas a partir do momento que mulheres foram instrumentalizadas enquanto Corpos Coloniais para uma política de governo. Assim, percebemos uma contradição entre o discurso e o objetivo real das políticas de planejamento familiar. A retórica (legitimada internacionalmente) que enfoca no "direito de escolha" e no "empoderamento da mulher", foi, na verdade, uma cortina de fumaça para a utilização de métodos de coerção na implementação de políticas de controle de natalidade. 


\section{REFERÊNCIAS BIBLIOGRÁFICAS}

Ballestrin, L. M. D. A. (2017). 'Feminismos subalternos', Revista Estudos Feministas, 25(3), p. $1035-1054$

CLADEM. (1999). Nada Personal: Reporte de Derechos Humanos sobre la aplicacion de la anticoncepcíon quirúrgica en el Perú - 1996-1998.

Connelly, M. (2009). Fatal misconception: The struggle to control world population. Cambridge: Harvard University Press.

Corrêa, S.; Petchesky, R. (1996). 'Direitos sexuais e reprodutivos: uma perspectiva feminista', Physis: Revista de Saúde Coletiva, Vol. 6, p. 147-177.

Crenshaw, K. (2002). 'Documento para o encontro de especialistas em aspectos da discriminação racial relativos ao gênero', Revista estudos feministas, 10(1), p. 171-188.

Davis, A. (2003). Racism, birth control and reproductive rights. In: Lewis, R; Mills, S. Feminist postcolonial theory: A reader, p. 353-367.

Dixon-Mueller, R. (1993). Population policy \& women's rights: Transforming reproductive choice. California: ABC-CLIO.

Fanon, F. (2008). Pele negra, máscaras brancas. Bahia: SciELO-EDUFBA.

Fujimori, A. (1995). 'Address to the Fourth World Congress on Women', Address given at the Fourth World Conference on Women, Beijing, October $15^{\text {th }}$. Disponivel em: https://www.un.org/esa/gopher-data/conf/fwcw/conf/gov/950915131946.txt [Acesso em: Set./Out. 2020].

Galeano, E. (1971). Las venas abiertas de América Latina. Mexico, DF: Siglo XXI.

Giddens, A. (1986). The nation-state and violence. Capital \& Class, 10(2), p. 216-220.

Giffin, K. (2002). 'Pobreza, desigualdade e eqüidade em saúde: considerações a partir de uma perspectiva de gênero transversal', Cadernos de Saúde Pública, Vol. 18, p. 103-112.

Gomes, M. S. (2013). 'O imaginário social <Mulher Brasileira> em Portugal: uma análise da construção de saberes, das relações de poder e dos modos de subjetivação', Dados, 56(4), p. 867-900

Gonzalez, L. (2020). Por um feminismo afro-latino-americano: ensaios, intervenções e diálogos / organização: Rios, F; Lima, M. 1a ed. Rio de Janeiro: Zahar. (Texto original publicado em 1988)

Hartmann, B. (1995). Reproductive rights and wrongs: the global politics of population control. Boston: South End Press.

Lugones, M. (2008). 'Colonialidad y género', Tabula Rasa, Vol. 9, pp. 73-101. 
Martínez-Echazábal, L. (1998). 'Mestizaje and the discourse of national/cultural identity in Latin America, 1845-1959', Latin American Perspectives, 25(3), pp. 21-42.

Miró, C. A. (1987). Políticas de população na América Latina em meados de 1985: um panorama confuso. Revista Brasileira de Estudos de População, 4(1), 87-94. Recuperado de https://rebep.org.br/revista/article/view/602

Neumann, I. B. (2008). 'Discourse analysis'. In: Klotz, A.; Prakash, D. Qualitative methods in international relations. Palgrave Macmillan, London, 61-77.

Oyěwùmí, O. (2004). 'Conceituando o gênero: os fundamentos eurocêntricos dos conceitos feministas e o desafio das epistemologias africanas', Tradução para uso didático de: Oyěwùmí, O. (2004). 'Conceptualizing Gender: The Eurocentric Foundations of Feminist Concepts and the challenge of African Epistemologies', African Gender Scholarship: Concepts, Methodologies and Paradigms, CODESRIA Gender Series, Vol. 1, p. 1-8.

Peru, Ministerio de Salud. (1996). Programa de Salud Reproductiva y Planificacion Familiar (1996-2000). Disponível em: http://bvs.minsa.gob.pe/local/minsa/315 PROG66.pdf.

Peru, Congreso de la República. (2003). Denuncia Constitucional № 151 contra Alberto Fujimori y sus ex ministros de salud: Eduardo Yong Motta, Marino Costa Bauer y Alejandro Aguinaga, por el delito de genocidio $y$ otros. Disponível em: https://1996pnsrpf2000.wordpress.com/fechas/.

Ragin, C. C. (2009). 'Introduction: Cases of "What is a case?"', In: Becker, H. S.; Ragin, Charles C. (Eds.) What is a case?: Exploring the foundations of social inquiry. Cambridge: Cambridge University Press.

Roland, E. (1995). 'Direitos reprodutivos e racismo no Brasil', Revista Estudos Feministas, 3(2), p. 506.

Scott, J. (1990). 'Gênero: uma categoria útil na Pesquisa Histórica', Educação e Realidade, 16(2).

Stavig, L. I. (2017). Feminist assemblages: Peruvian feminisms, forced sterilization, and paradox of rights in Fujimori's Peru. Dissertação de Doutorado, Antropologia/Lethbridge, Alta: University of Lethbridge.

Tilly, C. (1996). Coerção, capital e Estados europeus 1990-1992. São Paulo: EDUSP.

UNFPA, Brasil. (2007). Relatório da Conferência Internacional sobre População e Desenvolvimento, Conferência do Cairo. 